\title{
VI. Feuilleton.
}

\section{Die Fran in der Hygiene.}

Von Prof. Dr. J. Fodor.

(Fortsetzung aus No. 30.)

Die Hygiene der Mutter.

Die Frau wird allerwärts am böchsten als Mutter geachtet. Man schätzt in ihr das doppelte Leben, das an ihre Existenz geknüpft jst; man schätzt in ihr die Märtyrerin, die ibr eigenes Leben auf's Spiel setzt für ihren Sprössling, und bewundert in ihr die engelhafte Seele, welche diesen Bedroher und Peiniger ihres Lebens mit der ganzen Wärme ihres Herzens liebt und pflegt.

Die Sorge um die Gesundheit und den Schutz der Mutter ist sogar in die Seele der primitivsten Völkerschaften eingeprägt.

Auf den Inseln von Oceanien ist die Frau die Sclavin des Mannes, aber ill gesegneten Cmständen wird sie rom Manne in jeder Art gehegt und gepflegt. Bei den Aegyptern, den Griechen, Römern und anderen Völkern des Alterthums war, wie auch noch heute iu Siam, verboteu, die geseguete Frau vor Gericht zu fordern oder $\%$ n bestrafen. ${ }^{2}$ )

Auch die moderne Gesellschaft nimmt die Mutter in Schutz. Die englischen Gewerbegesetze schützen sie vor einer ïbermässigen Anstrengung bei Fabrik- oder Bergwerksarbeiten; sie bieten ilı sogar Gelegenheit, das Neugeborene zu pflegen. Durch unser Gewerbegeset 7 ist die Mntter nur vier Wochen nach dem Kindbette geschützt nnd zwar derart, dass sie während dieser Zeit zur Fabrikarbeit uicht verpflichtet werden $\mathrm{k}$ an $\mathrm{n}$. Welch ungen ügendes Gesetz, welch mangelhafte Firfahrung! Einmal müsste das Gesetz auch auf die Mutter, so lange sie gesegnet ist, erstreckt werden, wenigstens auf eine gewisse, gefährlichste Zeit dieses Znstandes; dann aber müsste es bindend sein auch für den liabrikanten, damit er sich nicht erkühne, die Mutter eben in der erwähnten Zeit mit Arbeit zu belasten. Ueberlässt man es der armen und unverstäudigen Mutter, von dem Schut\%e des Gesetzes Gebrauch \%u machen oder nicht, so erreicht man gar nichts. Man muss die Fabrikarbeiterinnen in ihrer Armuth und Habsucht kennen! Gedankenlos und unverständig setzen sie ilr eigenes Leben auf's Spiel, sogar das der Leibesfrucht, um nur einige wenige Kreuzer zu verdienen ... auf Branntwein fïr den Mann.

2) Vgl. H. Ploss, Das Weib. ju der Natur- und Völkerkunde. Leipzig 1887. II. Bd. p. $413 \mathrm{ff}$. 
In den Budapester Fabriken erleiden anf diese Weise Mutter und Kind ungeheuren Schaden, woranf ich dic Aufmerksamkeit der Gesetrgebung gan\% besonders gelenkt haben möchte!

Das wichtigste Capitel in der Hygiene der Mutter ist die Ernährung des Säuglings. Natur und Vorsehung haben dies der Frau 7.ur Pflicht gemacht, oder man könnte vielleicht sagen, ihr als herrliche Belohnung \%ugetheilt.

Die Frauen zahlreicher Völker halten die Ernährung des Sänglings für die grösste Wonne und ziehen sie darum gehörig in die Iänge. Die Indianerinuen Nordamerikas säugen ibre Kinder bis \%um 12. Jahre, die Frauen in Japan und China bis zum 10., aber auch in Europa kommt es vor: bei den Serben bis xum 4. and 5. Jahre, in Unter-Italien 3-4 Jahre lang, in Skandiuavien 2-3 Jahre lang. Wenn bei den Eingeborenen Paragnays die Mutter erkrankt oder stirbt, flehen andere Mütter den Vater au, den Säugling zur weiteren Eruährung ilonen zu überlassen (Ploss).

Bei den gebildeten Nationen Europas gewöhnen sich's die Frauen von Tag \%u Tag immer mehr und wehr ab, die Kinder selbst жil stillen - zum grossen Schaden beider Theile.

Besonders wird in den wohlhahenden Classen die eigene Ernährung des Säuglings so\%usagen als unschicklich oder doch wenigstens als peinliche last. ja sogar als Sehädigang der Gesundheit nnd Schönheit betrachtet. Wie verkehrt und wie irrig gedacht!

Das Traurigste daran ist aher, dass nunmehr auch unter dem Volke die Sitte der "Herrenlente", die kïnstliche Eruährung des Säuglings, um sich greift. und zwar zumeist aus Geiz. Um nur ihrem Verdienste, iller Arbeit nachgehen zu liönnen, überlässt die Nutter ihren Säugling alten Weibern oder halbwüchsigen Mädchen, die das unglückliche Geschöpf mit Milch, Brei, Brod und dergl. in wenigen Monaten unter die Erde bringen. Andere verdammen ihr Kind aus Nachlässigkeit oder Luverstand zur künstlichen Ernährung. manche aber thun es aus vorsätzlicher Böswilligkeit.

Diese Volkssitte hat ganz besonders in Süddeutschland. in Bayern und Württemberg, traurige Dimensionen angenommen. Es giebt dort ganze Gegenden, wo keine Frau mehr an die natürliche Eruährung des Säuglings denkt, und in Folge dessen ist dort die Sterblichkeit der Säuglinge eine erschreckend grosse; eine grössere sogar, als in Lngarn!

Eine Auseinandersetz.ung der Sterblichkeitsverhältnisse bei Säuglingen gehört eigentlich nicht in den Rahmen meines Vortrages, immerhin aber will ich durch einige Beispiele veranschaulichen, von welch entscheidendem Einflusse die Ernährung des Sänglings durch die Mutter auf das gauze Leben nnd die ganze Gesundheit ist.

Im ersten Lebensjahre sterben von 1000 lebend geborenen:1)

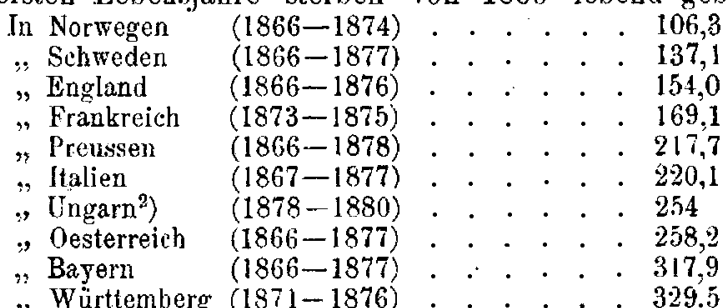

Zur vollen Würdigung dieser Ziffern muss wiederholt werden. dass in Norwegen und in Schweden, wo die Sterblichkeit der Sănglinge nur den dritten Theil der Sterblichkeit in Bayeru und Württemberg ausmacht, die Kinder nur von der Mutter gesäugt werden, wärend in den let\%tgenanuten Ländern die künstliche Emährung Mode ist.

In Bayern selbst ist die Sterblichkeit der Säuglinge besonders in der Limgebung von München eine eutsetzliche, währeed sie in der Provin\% um vieles geringer ist: in den Bezirken Oberbayern und Schwaben 406 und 409 (viermal soviel, als in Norwegen!), in der Pfalz dagegen nur 187.

In München und Umgebung solt die Ernährung der Säuglinge durch die Mutter vernachlässigt worden sein, seitdem nach den Analysen des berühmten Clemikers Liebig die irrige Meinung Verbreitung gefunden hat, dass das künstliche Kindernährmittel ebenso nahrhaft sei, wie die Muttermilch, da es chemisch genan soviel Nahrungsstoff enthält. Dieser unglücklichen Auffassung sind schon Tausende von Säuglingen zum Opfor gefallen, und es ist kaum mehr möglich, diesen Glauben im Volke auszurotten. Dabei wird die nuselige Sitte noch durch die marktsehreierischen Annonceli der gewissenlosen Fabrikanten erhalten und sogar verbreitet, die da haarscharf beweisen. dass ibre kiinstlichen Nahrungsmittel, ihre Kindermilch und Kindermehl nach den Analysen liervorragender Gelehrter (Iiiebig!) genau so nabrhaft sind, wie die Muttermilch. Was kümmert sich auch das Volk darum. dass nach den neuesten

1) Nach B odio. Vgl. H. Westergaard, Die Lehre von der Mortalität u. Jorbilität. Jena 1882 . p. 158.

2) S. Júng und Iekelfalussy, Magyarország népességi statistikảja Bevölkerungsstatistik von Ungarn). Budapest 1884. I. p. 907.
Berliner Beobachtungen bci. künstlicher Ernährung $14 \mathrm{Mal}$ soviel Kinder starben, als bei der Muttermilch; die Volkssitte hat nun einmal die billige und bequerne Art der kïnstlichen Ernährung eingefiihrt, diese verbreitet sich nun, und nur durch ausserordentliche Aistrengung wird es gelingen, das Volk \%ur natïrlichen Ernährung zarückzabringen und auf diese Weise das Leben der Săuglinge zu sehïtzen.

In welchem Maasse die künstliche Eruährung in Ungarn $11 \mathrm{~m}$ sich gegriffen hat, darüber kann ich mich nicht äussern, denn es fehlen mir diesbezäglichen Daten und Erfahrungen; so viel aber weiss ich, dass sie in Budapest sehr zu Hanse ist; wer in der Provinz lebt, wird aus seinen Erfahrungen mohr zu erzählen wissen - möge er es niclit unterlassen.

Wir müssen also aus hygienischen Gesichtspunkte wïnschen und darauf bestehen - wie es auch der Araber in Massauah von seiner Gattin fordert, widrigenfalls er sich vou ihr trennt und eine nimmt. die ilnr Kind sellıst säugt - dass auch die Mutter die Gesetze der Natur befolge, da sie sonst des Titels Mutter nicht würdig wäre.

Es mag übrigens Fälle geben, wo die Fran nicht im Stande ist, jenen $\Lambda$ uforderungen zu entsprechen, wo es der Arrt selbst verbietet - doch sind das Ausnahmen. Auch darf man sich ob $\Lambda$ rzt, ob Laie - bezüglich der ersehöpfenden Wirkung des Säugens nicht allausehr beunruhigen, - das sind Uebertreibungen. In den ersten Tagen schwächt es die Mutter, doch bald findet sich der Körper in seiner Entwickelung in die Umstände hinein. Und da wird die Mutter von der Natur nicht nur mit dem besseren Gedeihen des Kindes, nit den angenehmen natïrlichen Gefühle und dem beseligenden Bewusstsein der wohlerfüllten Pflicht, sondern auch mit eigener besserer Gesundheit belohnt. Der Appetit bessert sich, der Stoffwechsel ist rascher und besser. Nach einer alten Erfithrung der Frauenärzte Jeiden auch solche Frauen viel weniger an allen möglichen organischen Erkraukungen, als diejenigen, die sich vor dem Sängen zieren, oder zn faul, oder zum Säugen einfach unfähig sind.

Indem ich es so nachdrücklich betone, dass die Mutter den Säugling selbst stille, muss ich auch mit wenigen Worten der Umstände Erwähuung thun, welche die Befolgung dieses Rathes zuweilen unmöglich machen.

Am wichtigsten sind hier die allgemeinen hygienischen Factoren, welche die gesunde und kräftige Entwickelung des weiblichen Körpers fördern oder hemmen. Die gesunde, gnt entwickelte Frau kann aus ihreı Säuglingen Englein à la Rubens erziehen; die schwache, nervöse Frau, mit enger Brust und kaum entwickelten miitterlichen Organen wird ihre schwache Frucht auch kümmerlich kaum versehen können.

Die Ursache der schlechten Entwickelung jener Organe ist oft in der schlechten Bekleidung zu suchen. Viele Mütter rwingen die jungen Mädchen in enge Mieder - wie zwischen Bretter -, um nur eine gerade, stolze Haltung zu erzielen. Eine unvernünftige und unglückliche Mode!. Der enge "Geradehalter" presst den Brustkorb fortwährend zusammen und ist den Oryanen in ihrer Fntwickelung hínderlich; - schon in jungen Jahren verkünmern diese Organe. Weiss man doch, wie die Füsse der chinesischen Frauen durch enge Fussbekleidung verkrüppelt werden.

So versündigt sich die eitle Mutter an ihrer Tochter; sie verliudert in ihr die vollkommene Entfaltung der Schönheit und ertojdtet in ihr die Wonne und den Segen der Mutter.

Cnd was der grössten Beachtung werth ist: Die verkümmerten Brustorgane erben sich oft auch fort! Von Mutter \%u Mutter artet die formvollendetste Schönheit und die herrlichste Gabe der Mutter durch das unvernünftige Tragen des Mieders immer mehr aus. Diese Verliümmerung des Brustorgans ist in solchen Gegenden vollkommen erwiesen, wo selbst die Mädchen im Volke panzerartige Mieder tragen, wie $\%$ B. gerade in Bayern (Escherich) -, und in der That - eine hässlichere Erscheinung, als eine Frau aus der Gegend von von Dachau (bei München) kann ich mir kaum vorstellen: Die wahnsinnige Volksmode veranlasst sie, die Hüfte mit einer übertriebenen Polstejung auszurunden, die Brust aber mit einem panzerartigen Mieder eiozuschnüren und abzuffachen. Sie macht den Körper des Weibes zu einer waltren Carricalur und verdammt dev ungliicklichen Säugling z.u einer gekünstelten Kost.

Und wenn die Frauen immer allgemeiner ihre Brust einschnïren und die Mutterpflichten vernachlïssigen, wird das Weib nach der von Darwin festgestellten natïrlichen Gesetzmässigkeit der Aupassung nicht immer hässlicher werden und zur Ernährung des Säuglings nicht endlich ganz unbrauchbar werden? Es steht wahrhaftig zu befïrchten!

Aus alle dem ist zur Genüge ersichtlich, wie wichtig die Mutter in hygienischer Beziehung ist, von dem gesegneten Zustande an bis zur Auferziehung des Săuglings und Kindleins. Auch ist es klar, wie wichtig es ist, dass die Mutter die Pfichten, welche ihr die 
Natur auferlegt hat, kenne und erfülle. In dieser Richtung aber lässt sich am meisten durch richtige und allgemeine Aufklärung erreichen. Darum muss die Hygiene der Mutter für alle Schichten der Bevölkerung im verständigen und populären Schriften verbreitet werden.

(Fortsetzung folgt.) 